\title{
Cardionephrology: A Widespread Discipline for 21th Century Medical Students and Young Nephrology Residents
}

Rodolfo F. Rivera, ${ }^{1}$ Fulvio Floccari, ${ }^{2}$ Germán Diaz Parodi, ${ }^{3}$ Luca Di Lullo. ${ }^{4}$

\section{The Experience}

About the Author: Rodolfo F. Rivera is a graduate physician currently doing the first year of internship in Medical Statistics at the Pavia University, Italy. He is also the organizer of the Training Program in Cardiovascular Disease of the Society of Nephrology for medical students and residents.

Submission: Sep, 17, 2013 Acceptance: Dec. 31, 2014 Syndromes"."1
Heart and kidney diseases are closely related and the term "cardio - renal syndrome" is adopted worldwide to underline that linkage. Richard Bright recognized that "hypertrophy of the heart seems in some degree to have kept pace with the advance of the disease in the kidneys"1 and, after him, George Johnson ${ }^{2}$, William Gull, Henry Sutton ${ }^{3}$, Franz Volhard, Theodor Fahr ${ }^{4}$, and Henry Coldblatt ${ }^{5}$ confirmed Bright's hypothesis. In 1956, Gabriele Monasterio et $\mathrm{al}^{6}$, the Pisa School of Medicine introduced the term "Renal Cardiopathy". Further meetings, such as Strasburg ${ }^{8}$, Giessen ${ }^{9}$ and especially Assisi Cardionephrology meeting, have emphasized this relationship, after 25 years of experience largely thanks to Professor Timio. ${ }^{10}$ on the other hand, the Advanced Dialysis Quality Initiative, led by Prof. Claudio Ronco from Vicenza (Italy), has contributed greatly to the definition and classification of the "Cardio-Renal

\section{The Italian Context of Cardionephrology}

The Italian Society of Nephrology (SIN) has recently approved (April 2012) the foundation of the Cardionephrology Study Group (CN-SG) directed by Dr. Luca Di Lullo together with Dr. Antonio De Pascalis (secretary) and other four advisers (Dr. Emiliana Ferramosca, Dr. Antonio Bellasi, Dr. Rodolfo F. Rivera and Prof. Mario Timio), (figure 1). SIN has commissioned them to discuss and achieve specific clinical, scientific (national meetings) and educational goals (residential stages in cardiovascular diagnosis) in cardio-renal medicine, engaging medical students and nephrology residents.

\section{New Formative Runs for Students and Young Doctors}

On April $4^{\text {th }}$ and $5^{\text {th }}, 2013$, the first annual meeting of CN-SC took place near Rome, in the presence of outstanding speakers (both cardiologists and nephrologists) and over 150 delegates. Scientific sessions have focused on coronary artery disease and chronic heart failure, vascular and cardiac calcifications, Fabry disease and amyloidosis, resistant hypertension and other new insights in cardio - renal diseases.

CN-SG is also involved in planning several research protocols; at
Figure 1. Cardionephrology Study Group of the Italian Society of Nephrology. (First line from left to right: Antonio De Pascalis, Emiliana Ferramosca, and Mario Timio; second line from left to right: Rodolfo F. Rivera, Antonio Bellasi and Luca Di Lullo)

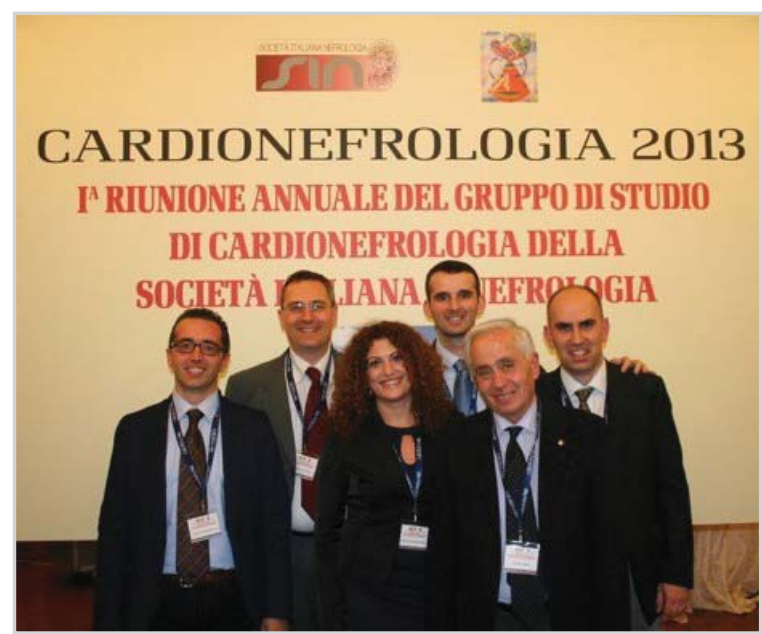

the present time, more than 400 patients were enrolled in three clinical studies. This research activity has an increasing participation of students and the consequent production of new graduation thesis. During the last two years, several papers were published in national| ${ }^{12,13}$ and international| ${ }^{14,15,18}$ journals.

CN-SG has also promoted close collaborations with cardiologists to provide further research opportunities for both medical students and residents in nephrology and cardiology, interested in cardiovascular medicine.

In May 2013, CN-SG was invited to the Italian Cardiovascular UItrasound Society (SIEC) annual meeting to collect a symposium about cardio - renal interactions and ultrasound diagnostic tools. From this opportunity the group has presented preliminary data about right ventricular dysfunction in chronic kidney disease patients. ${ }^{16}$ Therefore, CN-SG was also invited by the European Cardionephrology Association (ECNA) to take part on 1st Southeastern Europe Cardionephrology and Hypertension

\footnotetext{
${ }^{1}$ Nephrology Division, San Gerardo Hospital, University of Milan-Biccoca, Monza, Italy

${ }^{2}$ Department of Nephrology and Dialysis, San Paolo Hospital, Civitavecchia, Italy

${ }^{3}$ Department of Medicine, Iturraspe Hospital, University of Litoral, Santa Fe, Argentina

${ }^{4}$ Department of Nephrology and Dialysis, L. Parodi Delfino Hospital, Colleferro, Italy

Correspondence:

Rodolfo F. Rivera

Address: Via Pergolesi 33, 20050 Monza (MB), Clinica Nefrologica, A.O. Ospedale San Gerardo.

Email: rodolfofrivera@gmail.com
} 
Congress in Nis (Serbia) in a round table on right ventricular failure and chronic kidney disease (CKD). ${ }^{17}$

\section{Research Opportunities for Undergraduates and Graduate Levels}

Together with study group constitution, the Italian Society of Nephrology council has approved three multicentric research protocols proposed by CN-SG for the next three years. The first one is related to the evaluation of incidence and prevalence of right ventricular dysfunction in Stage III - IV CKD patients. Actually, more than 400 patients were enrolled and preliminary data were available. ${ }^{18}$ The second one concerns the predictive value of bioimpedance analysis in patients with chronic heart failure and chronic kidney disease; the study is currently in the enrolling stage. The last one is focused on evaluating cardiovascular assessment (especially incidence and prevalence of pericardial effusion) in patients with familial polycystic kidney disease. This study has a case-control design with 220 patients and more than 300 controls currently enrolled.

Figure 2. Dr. P. Poleggi during the training on Basic Life Support- Defibrillation (BLS-D)

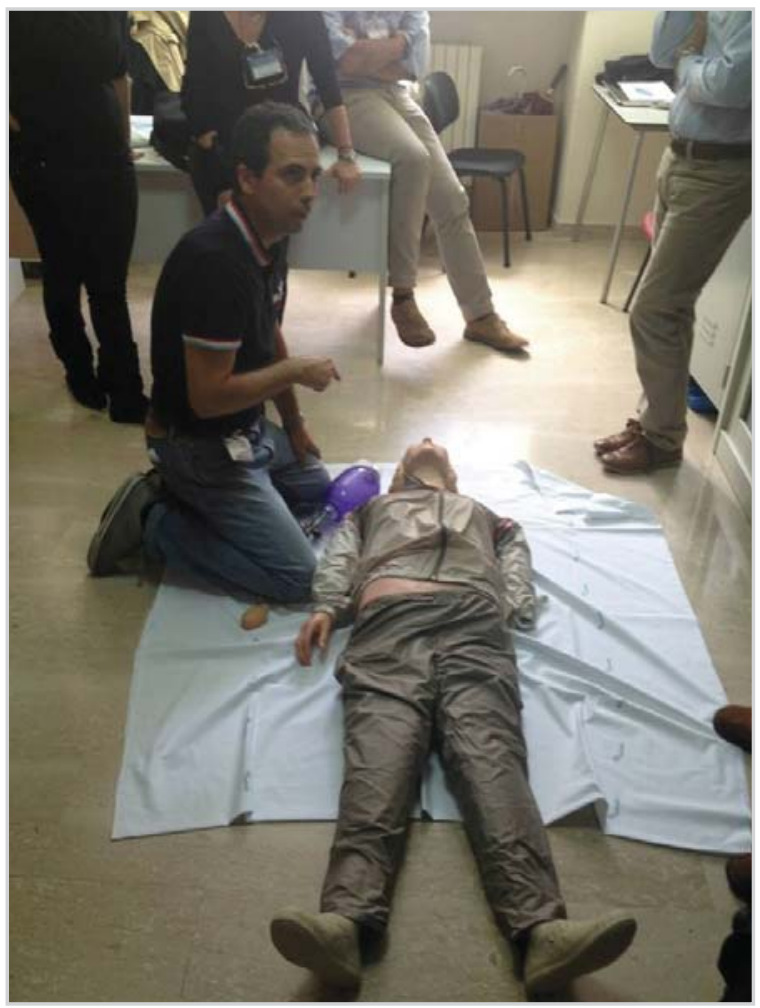

The three ongoing research protocols are giving a great opportunity to several students to be involved in research at an undergraduate level.

\section{New Clinical Stages and Fellowship}

on the educational front, CN-SG provided "residential stages" for all medical students and nephrology residents required to be confident with diagnostic approach to cardiovascular disease. The educational program includes practical sessions on electrocardiography and echocardiography diagnostic devices
Figure 3. Dr. L. Di Lullo during an echocardiographic practical exercise.

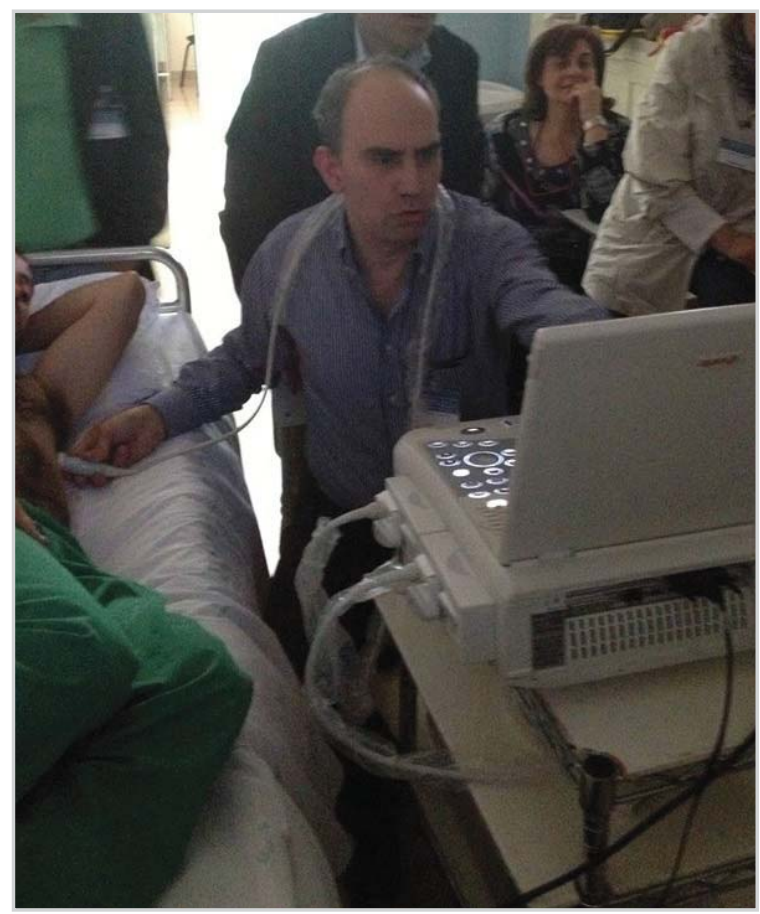

together with complete training on Basic Life Support- DefibriIlation (BLS-D) (figure 2). All tutors are certified by respected scientific societies such as SIEC (figure 3). New dates are planned in 2013 and 2014.

CN-SG has recently also involved in educational training of Italian post-graduate schools of Nephrology by setting up seminars of Cardionephrology for medical students and residents. Students coming from the Internal Medicine Division of Iturraspe Hospital in Santa Fe, Argentina (Litoral National University) performed three months of clinical stages at the Nephrology division in San Gerardo Hospital, Monza, Italy (Milano-Bicocca University), a helpful experience to share different ways of managing daily nephrology practice.

All CN-SG activities, courses, downloadable material and other news are available on the internet (http://www.sin-cardionefrologia.it/). 


\section{Experience}

\section{References}

1. Bright, Richard. Tabular view of the morbid appearances in 100 cases connected with albuminous urine. Guy's Hospital Reports 1836; 1:380.

2. Johnson, G. On the disease of the Kidney. John Park Son Lond. 1852; 131. 3. Gull Ww. On the Pathology of the Morbid State Commonly Called Chronic Bright's Disease with Contracted Kidney... Medico-Chir Trans Garrison Morton. 1872; 37:4215.

4. Volhard F, Fahr, T. Die Brightscht Nierekrankheit. Klinik, Pathologie und Atlas. Springer, Berlin. 1914; 115-43.

5. Goldblatt H, Lynch J, Hanzal RF, Summerville WW. Studies on experimental hypertension: I. The production of persistent elevation of blood pressure by means of renal ischemia. J Exp Med. 28 febbraio 1934; 59(3):347-79.

6. Timio M. XIII Congresso Societa' Italiana di Cardiologia 1956, in Trieste and the birth of cardionephrology. G Ital Nefrol. 2007; 24(6):600-4.

7. Monasterio G, Gigli G, Donato L, Muiesan, G. La Cardiopatia Renale. Atti Soc Ital Cardiol. 1956; XVIII Congresso, Trieste:7-56.

8. Jahn H, Massry S, Ritz E, Weidmann P. Cardiocirculatory Function in Renal Disease. Basel: S Karger Ag; 1984.

9. Wizemann V, Kramer W, Schütterle $G$. The heart in end-stage renal failure: etiology, symptoms, and management of uremic heart disease. Basel: Karger; 1986.

10. Timio M, Venanzi S. Cuore e rene. Abetre Edizioni. Milano; 1987.
11. Ronco C, Haapio M, House AA, Anavekar N, Bellomo R. Cardiorenal syndrome. J Am Coll Cardiol. 2008; 52(19):1527-39.

12. Rivera R, Floccari F, Di Lullo L, Granata A, Logias F, D'Amelio A, et al. La malattia renale cronica e il trattamento dello scompenso cardiaco, il ruolo del cardionefrologo. Tecniche Nefrologiche e Dialitiche. 2012;1(24):82-94.

13. Bellasi A, De Pascalis A, Di Lullo L, Ferramosca E, Rivera R, Timio M. GdS di Cardionefrologia: attualità e prospettive future. G Ital Nefrol. 2013. 30 (2):1-3. 14. Di Lullo L, Floccari F, Santoboni A, Barbera V, Rivera RF, Granata A, Morrone $L$, Russo D. Progression of cardiac valve calcification and decline of renal function in CKD patients. J Nephrol. 2013;12;26(4):739-44.

15. Di Lullo L, Floccari F, Rivera R, Barbera V, Granata A, Otranto G, Mudoni A, Malaguti M, Santoboni A, Ronco C. Pulmonary Hypertension and Right Heart Failure in Chronic Kidney Disease: New Challenge for 21st-Century Cardionephrologists. Cardiorenal Med. 2013;3:96-103.

16. ECOCARDIOGRAFIA 2013. XVI Congresso Nazionale, Società Italiana di Ecografia Cardiovascolare (SIEC). Available at: http://www.siec.it/congresso/ index.php

17. KARNEF 2013. 1st Southeastern Europe Cardionephrology and Hypertension Congress. Available at: http://www.karnef.org/cms/index.php/en/ 18. Floccari F, Granata A, Rivera R, Marrocco F, Santoboni A, Malaguti M, et al. Echocardiography and right ventricular function in NKF stage III chronic kidney disease: Ultrasound nephrologists' role. J Ultrasound. 2012;15(4):252-6.

\section{Acknowledgments}

None

Conflict of Interest Statement ct Funding

The authors have no funding, financial relationships or conflicts of interest to disclose.

Cite as:

Rivera RF, Floccari F, Diaz-Parodi G, Di Lullo L. Cardionephrology: A Widespread Discipline for 21th Century Medical Students and Young Nephrology Residents. Int J Med Students. 2014;2(1): 25-7. 